\title{
Research
}

\section{The use of magnesium sulphate and morphine vs. morphine-only in Irukandji syndrome: a retrospective review of ambulance data}

John Rathbone BHIthSc (EmergMed), GradCertResearch'; Richard Franklin PhD, FPHAA, FARLF, is Lecturer'; Vasilios Nimorakiotakis MBBS, FACEM, FACRRM, is an emergency physician and Deputy Director ${ }^{2}$

\section{Affiliations:}

1James Cook University, Townsville, Queensland

${ }^{2}$ Emergency Department, Epworth Hospital, Melbourne, Victoria

https://doi.org/10.33151/ajp.16.711

\section{Abstract}

\section{Introduction}

In 2006, the Queensland Ambulance Service (QAS) approved the use of magnesium sulphate for the management of patients with Irukandji syndrome (IS). The aim of this study was to compare pain scores and hypertensive (systolic BP $\geq 140 \mathrm{mmHg}$ and/or diastolic $\mathrm{BP} \geq 90 \mathrm{mmHg}$ ) patients who received intravenous morphine as their treatment (morphine group) over those who received a combination of intravenous morphine and magnesium (magnesium group).

\section{Methods}

A retrospective case review of all IS patients attended by the QAS between 2007 and 2014. A search of the QAS electronic data base found 112 patients had IS. Analyses in IBM SPSS v.22 was undertaken to determine the outcome in final pain scores and blood pressure between the two groups.

\section{Results}

Pain reduction was statistically different $(F=29.18 ; p<.01)$, between the morphine group and the magnesium group with mean numerical pain scores post-treatment of 4.91 (95\% Cl: 4.02-5.81) and 2.21 (95\% Cl: 1.66-2.76) respectively. There was a lower frequency of patients in the magnesium group who remained hypertensive on arrival at a medical facility, with a significant difference between mean arterial BP of $101 \mathrm{mmHg}(95 \% \mathrm{Cl}: 96-105 ; \mathrm{p}=.028)$ and diastolic BP of $84 \mathrm{mmHg}(95 \% \mathrm{Cl}: 80-88 ; p=.029)$ post-treatment. Of the 54 hypertensive cases in the magnesium group, 32 were normotensive post-treatment compared to only six from the morphine group $(n=17)$.

\section{Conclusion}

There has been considerable difference of opinion as to the utility of magnesium in IS and a marked difference in the results of case series versus a small randomised control trial. This study suggests that the combination of morphine and magnesium is more effective in treating patients with IS than morphine alone.

Keywords:

Irukandji; box jellyfish; magnesium; morphine; pain; hypertension 


\section{Introduction}

Irukandji syndrome (IS) is a painfully debilitating marine envenomation attributed to stings from jellyfish of the Class Cubozoa; Order Carybdeida $(1,2)$. There are currently 14 known species of jellyfish from the Order Carybdeida that inhabit the tropical waters of Australia $(1,2)$. Of that number, 11 species are presumed to have caused IS (1-3).

Irukandji syndrome has been recorded along the entire Queensland coast (4), with an increase in incidences in the northern regions. However, the syndrome is not just restricted to Australia, with reports of IS in Hawaii, Thailand, Florida and the Philippines, as well as in the cooler waters of the United Kingdom (4). The symptomology of IS is suggestive of a catecholamine storm (5). Based on this premise, Corkeron first reported the successful use of magnesium sulphate in a 26 year-year-old male with IS in 2003 (6). Although the patient had previously received morphine and diazepam, he was still profusely diaphoretic, agitated and had continuous abdominal discomfort. Due to continued hypertension $(170 / 100 \mathrm{mmHg})$, it was decided to start a therapeutic trial of magnesium. During the initial loading dose $(10 \mathrm{mmol} / \mathrm{L})$ the patient had a resolution of symptoms with pain on the verge of resolving (6).

Magnesium is an established therapy for a number of hyperadrenergic conditions, such as phaeochromocytoma and pre-eclampsia, as well as asthma and cardiac arrhythmia (7). It has not only a depressive effect on the release of systemic catecholamines but is also known to produce a fall in systemic vascular resistance in hyperadrenergic settings (7).

However, magnesium toxicity can develop when serum concentrations exceed 1.74-2.61 mmol/L, with mild cases presenting with nausea, vomiting and facial flushing. Significant cardiovascular conditions such as hypotension, shortness of breath, arrhythmias and cardiac arrest have been recorded in severe cases of toxicity (7).

There have been case reports and a single randomised control trial reporting various degrees of success and failure with magnesium (8). A recent systematic review of the use of magnesium concluded that there is currently poor clinical evidence to recommend the use of magnesium and inconclusive evidence to withdraw use where this is already occurring' (9). For the majority of IS cases the initial contact is innocuous, with minor pain and few skin lesions being visible (3). However, some species, such as Malo maxima from Western Australia and Morbakka fenneri from Queensland, cause significant pain on contact together with noticeable skin lesions (3). Fenner (10) and Carrette (11) report in detail the signs and symptoms of IS.

\section{Background}

The Queensland Ambulance Service (QAS) is the only pre- hospital ambulance service in Queensland. Since 2007 the QAS has collected and maintained an electronic database of all patient cases, using the mobile Electronic Ambulance Report Form (eARF) completed by paramedics using laptop technology (12). Periodic quality assurance and data cleaning and maintenance is performed on the entire dataset by the Information Support Unit (12).

QAS protocol for the administration of magnesium in the IS setting at the time of this data was: intractable pain unrelieved by narcotic analgesia and/or systolic BP $>160 \mathrm{mmHg}$. Adult dose: $20 \mathrm{mmol} / \mathrm{L}$ magnesium loading dose over 15 minutes followed immediately with a maintenance dose of $20 \mathrm{mmol} / \mathrm{L}$ over 60 minutes (500 mL $0.9 \%$ saline) (13).

\section{Methods}

All patients in this study were attended by the QAS from 1 January 2007 to 31 December 2014.

In December 2006, magnesium was introduced for the management of IS by intensive care paramedics and with its service-wide introduction in September 2011, provided a unique opportunity to examine the difference between treatment protocols. Between December 2006 and September 2011, advanced care paramedics were restricted to the use of intravenous morphine for analgesic management. An adult starting dose of $2.5-5 \mathrm{mg}$ bolus is repeated every 10 minutes until the desired therapeutic effect has been reached, to a maximum of $20 \mathrm{mg}$ (14).

The initial data set was obtained by extracting QAS patient data from 1 January 2007 to 31 December 2014 with the Medical Priority Dispatch System Inc. (MPDS) (15) Code 2 (Allergies (reactions)/Envenomations (stings, bites). The QAS Information Support, Research and Evaluation Unit provides an overview of all research activities and undertakes approved research requests for specific data within the patient data base. This request resulted in 8653 patients being identified. In order to refine the search to identify Irukandji injuries, a word search was undertaken using 'jellyfish - jelly fish - Irukandji - Irukandji syndrome', resulting in 605 patients remaining in the data set. A further word search using 'magnesium' in the treatment section of the remaining cases resulted in 77 patients being identified. Magnesium is indicated for a number of medical conditions within QAS protocols, including IS. Due to the possible misspelling of Irukandji, a manual search was conducted of the remaining 528 patients to identify IS by descriptive text of signs and symptoms. This manual search resulted in a further 35 IS patients being identified, who had received only morphine for their IS management (Figure 1). All children less than 12 years of age were removed from the data; all children more than 12 years of age received adult drug doses, unless otherwise stated (13). The search was undertaken independently by two authors (Rathbone, Franklin). 


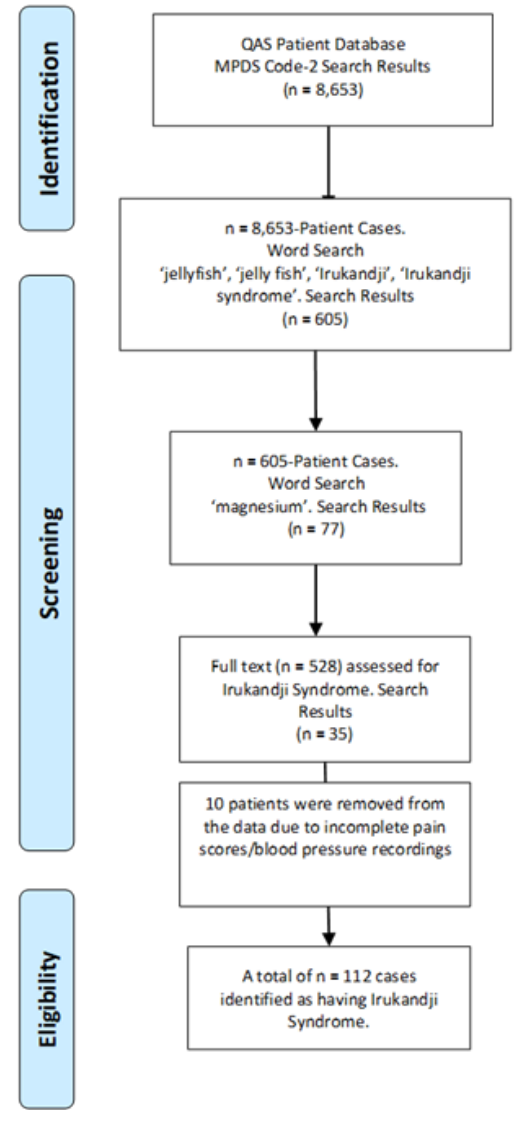

Figure 1. QAS database search
Once identified, over 40 relevant clinical and situational variables were extracted for each case (Table 1). These variables were extracted into an Excel spreadsheet for cleaning and coding and then exported to IBM SPSS v.22 for analysis.

Pain score was measured via the numeric rating scale from 0 to 10 . Initial pain scores of all patients were recorded by paramedics on their arrival at the scene, and a final pain score was noted on their arrival at a medical facility. The initial and final pain scores were collected and placed into their relevant group, thus providing a pain score before the commencement of treatment and on their arrival at a hospital post-parenteral analgesic management. The same recording and data collection methods were undertaken for hypertension.

Adult hypertension was defined as having systolic $B P \geq 140$ $\mathrm{mmHg}$ and/or a diastolic BP $\geq 90 \mathrm{mmHg}(16)$. This was then used to create a dichotomous variable of hypertensive patients from each group.

Analysis was undertaken in Microsoft Excel for Office 365 and IBM SPSS v22. Statistical significance was determined where $p$ was less than $<0.05$. Microsoft Excel data analysis tools and descriptive statistics were used to calculate $95 \%$ confidence intervals for pain scores. An independent samples t-test was used to test for significance on BP and the Wilcoxon signed ranks test and sign rank test were used to analyse final and initial pain scores within the same group and group versus group (Table 2).

Table 1. Extracted variables

\begin{tabular}{|c|c|c|c|c|c|}
\hline \multicolumn{6}{|l|}{$\begin{array}{c}\text { Patient } \\
\text { demographics }\end{array}$} \\
\hline Gender & Age & $\begin{array}{l}\text { Circumstance of } \\
\text { sting }\end{array}$ & $\begin{array}{l}\text { Geographical location } \\
\text { of incident }\end{array}$ & Patient residency & $\begin{array}{l}\text { Location of patient } \\
\text { (coastal, offshore, } \\
\text { unknown) }\end{array}$ \\
\hline \multicolumn{6}{|l|}{$\begin{array}{l}\text { Circumstance of sting } \\
\text { (eg. swimming, diving, } \\
\text { surfing) }\end{array}$} \\
\hline \multicolumn{6}{|l|}{ Clinical symptoms } \\
\hline Back pain & Chest pain & Nausea & Vomiting & Headache & Diaphoresis \\
\hline Initial pain score & Final pain score & $\mathrm{BP}$ & Abdominal pain & Generalised pain (limbs) & Distressed/agitation \\
\hline Hypertensive & Hypotensive & Initial appearance & Final appearance & Initial BP & Final BP \\
\hline $\begin{array}{l}\text { Mean arterial pressure } \\
\text { (MAP) }\end{array}$ & $\begin{array}{l}\text { Sting location on } \\
\text { body }\end{array}$ & & & & \\
\hline \multicolumn{6}{|l|}{ Clinical management } \\
\hline $\begin{array}{l}\text { Morphine administered } \\
(\mathrm{Y} / \mathrm{N})\end{array}$ & $\begin{array}{l}\text { Morphine dose } \\
(\mathrm{mg})\end{array}$ & $\begin{array}{l}\text { Morphine effective } \\
(\mathrm{Y} / \mathrm{N})\end{array}$ & $\begin{array}{l}\text { Magnesium } \\
\text { administered (Y/N) }\end{array}$ & Magnesium dose (mmol) & $\begin{array}{l}\text { Magnesium effective } \\
(\mathrm{Y} / \mathrm{N})\end{array}$ \\
\hline \multicolumn{6}{|l|}{ Other variables } \\
\hline Date of incident & Day of incident & $\begin{array}{l}\text { Time ambulance } \\
\text { dispatched }\end{array}$ & $\begin{array}{l}\text { Time ambulance } \\
\text { arrived on scene }\end{array}$ & Doctor on scene $(\mathrm{Y} / \mathrm{N})$ & $\begin{array}{l}\text { Type of patient } \\
\text { recovery vehicle } \\
\text { (ambulance, } \\
\text { helicopter, boat) }\end{array}$ \\
\hline Time at hospital & $\begin{array}{l}\text { Incident } \\
\text { occurred within } \\
\text { stinger net }(\mathrm{Y} / \mathrm{N})\end{array}$ & $\begin{array}{l}\text { The application of } \\
\text { vinegar }(\mathrm{Y} / \mathrm{N})\end{array}$ & & & \\
\hline
\end{tabular}


Table 2. Analysis within groups

\begin{tabular}{|l|}
\hline a. Data_Set_Groups $=$ \\
\hline b. Final_Pain $<$ Initial_Pain \\
\hline c. Final_Pain $>$ Initial_Pain \\
\hline d. Final_Pain $=$ Initial_Pain \\
\hline
\end{tabular}

\section{Ethics}

Ethics approval was provided by James Cook University, Human Research Ethics Committee (Application ID H6456).

\section{Results}

There were 112 IS patients transported by QAS from 2007 to 2014 ( $n=65$ male, $n=47$ female). Their data was then placed into two groups: morphine only group $(n=35)$, in this group their course of treatment was morphine sulphate. The other group, magnesium ( $n=77$ ), had a combination of morphine and magnesium sulphate as the course of treatment (Table 3).

\section{Analgesia}

There was no significant difference between the pain scores of both groups before commencement of treatment. The mean pain score for the morphine group before treatment was 7.9 (95\% Cl: $7.23-8.60)$ and 7.8 (95\% Cl: 7.21-8.33) for the magnesium group ( $F=0.09 ; p=.76)$ (Figures 2 and 3 ).

On arrival at a medical facility the recorded final pain scores demonstrated a significant difference between both groups and from within the groups. The mean pain score post-treatment for the morphine group was 4.9 (95\% Cl: 4.02-5.81), and the magnesium group: 2.2 (95\% Cl: 1.66-2.76), $F=29.18 ; p<.01)$ (Figure 4 and Table 4). The Wilcoxon test, and sign rank test results indicated that morphine alone reduces pain more significantly by five standard deviations $(z-4.877 c p=<.001$ and $z-5.388 p=<.001$, respectively). The Wilcoxon test and sign rank test results indicated that the magnesium and morphine reduced pain more significantly by 7 to 8 standard deviations (z-7.019c $p=<.001$ and $z-7.938 p=<.001$ respectively). It can be deduced from these analyses that magnesium and morphine are more potent than morphine alone in reducing pain in IS patients.

Of the $n=35$ patients in the morphine group, one patient $(2.8 \%)$ was pain free on arrival at hospital. In the magnesium group, $19(27.1 \%)$ patients had no pain on arrival at hospital, including three patients with pain scores of 10 becoming pain free during the loading administration of magnesium. There was no significant difference in pain scores between females and males $(F=2.2 ; p=.141)$.

Seven patients from the magnesium group were excluded as their initial pain scores were documented as being 'unable to rate'. The morphine group received on average $10.4 \mathrm{mg}$ morphine $(\mathrm{SD}=6.4$ ) while the magnesium group received an average of $11.6 \mathrm{mg}$ morphine (SD=8.4), there was no statistical difference between morphine dose in both groups $(F=0.45$; $p=.504)$.

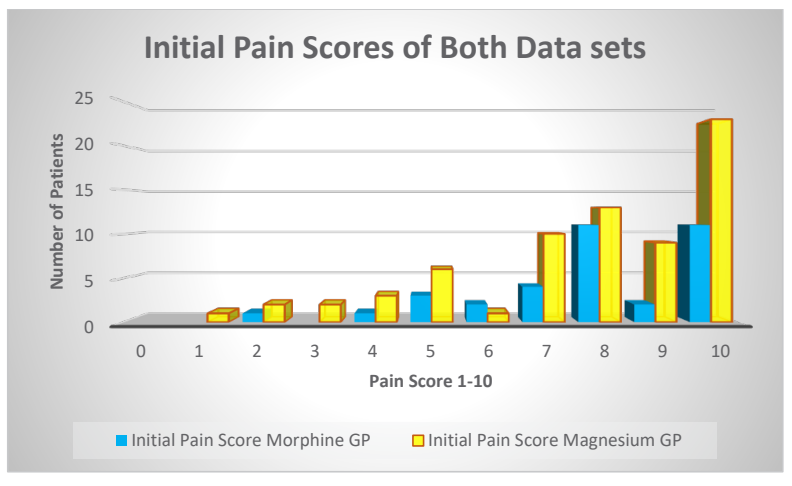

Figure 2. Initial pain scores of both groups before commencement of treatment

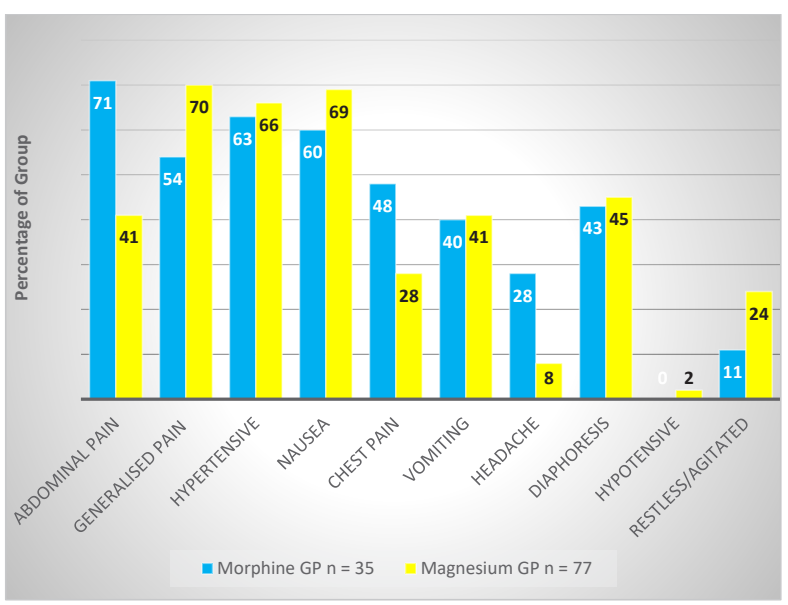

Figure 3. Post-treatment pain score comparison of both groups

\section{Blood pressure}

A total of 74 patients were hypertensive at the commencement of treatment, three had only the systolic BP reading documented and were subsequently removed from the data. Those who received magnesium (54 patients) were unlikely to be hypertensive on arrival at a medical facility. Of the 54 hypertensive patients in the magnesium group, $n=32(59 \%)$ were normotensive on arrival at a medical facility, whereas in the morphine group, $n=6(35 \%)$ hypertensive patients were normotensive on arrival at a medical facility.

There was no significant difference between both groups before commencement of treatment systolic $F(1,69)=.489, p=.487$, diastolic $F(1,68)=3.301, p=.074$ and mean arterial pressure $F(1,68)=3.244, p=.0 .76$. However, there was a significant difference with the reduction in MAP and diastolic BP after treatment in the magnesium group, $F(1,68)=5.061, p=.028$ and $F(1,68)=5.079, p=.027$ respectively, when compared to the morphine group on arrival at a medical facility (Table 5). Two patients from the magnesium group became hypotensive ( $87 / 64 \mathrm{mmHg}$ and $90 / 60 \mathrm{mmHg}$ ) which was corrected by the cessation of magnesium and administration of $0.9 \%$ saline. No side effects were reported within the morphine group. 
Rathbone: Irukandji syndrome: a retrospective review of ambulance data

Australasian Journal of Paramedicine: 2019;16

\begin{tabular}{|c|c|c|c|}
\hline & 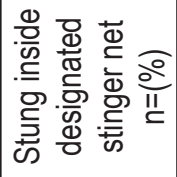 & \multicolumn{2}{|c|}{ 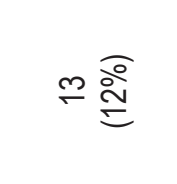 } \\
\hline & 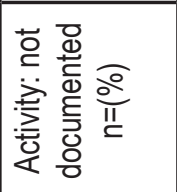 & \multicolumn{2}{|c|}{$\stackrel{\widehat{N}}{\stackrel{\mathrm{N}}{ }}$} \\
\hline & 竞焉高 & \multicolumn{2}{|c|}{$-\stackrel{\widehat{\circ}}{\stackrel{0}{e}}$} \\
\hline & 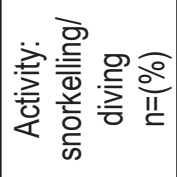 & \multicolumn{2}{|c|}{ 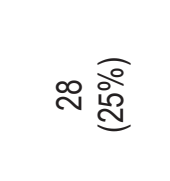 } \\
\hline & 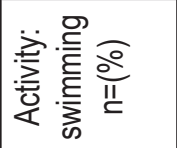 & \multicolumn{2}{|c|}{ 品 } \\
\hline & 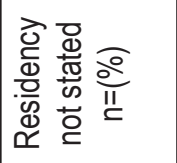 & \multicolumn{2}{|c|}{ 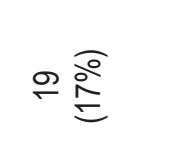 } \\
\hline & 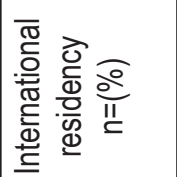 & \multicolumn{2}{|c|}{$\stackrel{\overparen{a}}{\stackrel{\circ}{=}}$} \\
\hline & 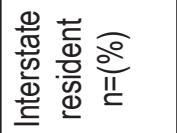 & \multicolumn{2}{|c|}{$\cong \stackrel{\widehat{\circ}}{\equiv}$} \\
\hline & 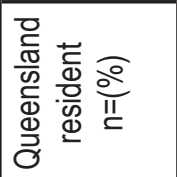 & \multicolumn{2}{|c|}{ \& } \\
\hline & 娄 & $\stackrel{d}{\sim}$ & $\stackrel{\infty}{\sim}$ \\
\hline & 剩 z & \multicolumn{2}{|c|}{$\stackrel{\cong}{\cong}$} \\
\hline & 음 & $\stackrel{\infty}{m}$ & $\hat{N}$ \\
\hline & 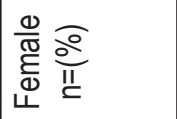 & $\forall$ 六 & m \\
\hline & 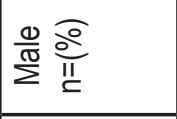 & 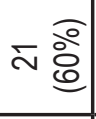 & $\forall \frac{a}{2}$ \\
\hline 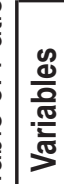 & $\begin{array}{l}\text { 을 } \\
\text { 인 }\end{array}$ & $\begin{array}{l}\stackrel{\text { 를 }}{\frac{0}{2}} \\
\text { 흘 }\end{array}$ & 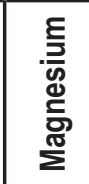 \\
\hline
\end{tabular}



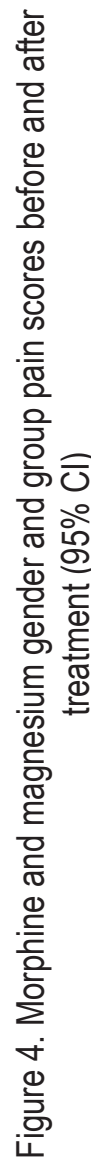


Rathbone: Irukandji syndrome: a retrospective review of ambulance data

Australasian Journal of Paramedicine: 2019;16

Table 4. Gender and group specific 95\% confidence intervals for numerical pain scores

\begin{tabular}{|c|c|c|c|c|c|c|c|c|c|c|}
\hline & \multirow{2}{*}{ Data set } & \multirow{2}{*}{$\begin{array}{c}\text { Gender } \\
\begin{array}{l}\text { Group } \\
\text { totals }\end{array}\end{array}$} & \multirow{2}{*}{$\mathbf{N}$} & \multirow{2}{*}{ Mean } & \multirow{2}{*}{$\begin{array}{c}\text { Std. } \\
\text { deviation }\end{array}$} & \multirow{2}{*}{$\begin{array}{l}\text { Std. } \\
\text { error }\end{array}$} & \multicolumn{2}{|c|}{$95 \% \mathrm{Cl}$ for mean } & \multirow{2}{*}{ Minimum } & \multirow{2}{*}{ Maximum } \\
\hline & & & & & & & $\begin{array}{l}\text { Lower } \\
\text { bound }\end{array}$ & $\begin{array}{l}\text { Upper } \\
\text { bound }\end{array}$ & & \\
\hline \multirow{6}{*}{$\begin{array}{c}\text { Initial } \\
\text { pain }\end{array}$} & \multirow{3}{*}{$\begin{array}{l}\text { Morphine } \\
\text { group }\end{array}$} & Male & 21 & 7.57 & 2.27 & 0.495 & 6.64 & 8.61 & 2 & 10 \\
\hline & & Female & 14 & 8.42 & 1.45 & 0.388 & 7.59 & 9.27 & 5 & 10 \\
\hline & & $\begin{array}{c}\text { Group } \\
\text { total }\end{array}$ & 35 & 7.91 & 2.00 & 0.338 & 7.23 & 8.60 & 2 & 10 \\
\hline & \multirow{3}{*}{$\begin{array}{l}\text { Magnesium } \\
\text { group }\end{array}$} & Male & 42 & 7.55 & 2.38 & 0.367 & 6.81 & 8.29 & 2 & 10 \\
\hline & & Female & 28 & 8.11 & 2.33 & 0.440 & 7.20 & 9.01 & 1 & 10 \\
\hline & & $\begin{array}{c}\text { Group } \\
\text { total }\end{array}$ & 70 & 7.82 & 2.36 & 0.282 & 7.21 & 8.33 & 1 & 10 \\
\hline \multirow{6}{*}{$\begin{array}{l}\text { Final } \\
\text { pain }\end{array}$} & \multirow{3}{*}{$\begin{array}{l}\text { Morphine } \\
\text { group }\end{array}$} & Male & 21 & 4.67 & 2.81 & 0.614 & 3.38 & 5.95 & 0 & 10 \\
\hline & & Female & 14 & 5.28 & 2.33 & 0.623 & 3.94 & 6.63 & 1 & 9 \\
\hline & & $\begin{array}{l}\text { Group } \\
\text { total }\end{array}$ & 35 & 4.91 & 2.61 & 0.442 & 4.02 & 5.81 & 0 & 10 \\
\hline & \multirow{3}{*}{$\begin{array}{l}\text { Magnesium } \\
\text { group }\end{array}$} & Male & 42 & 2.20 & 2.45 & 0.382 & 1.42 & 2.97 & 0 & 9 \\
\hline & & Female & 28 & 2.24 & 2.13 & 0.395 & 1.43 & 3.05 & 0 & 6 \\
\hline & & $\begin{array}{c}\text { Group } \\
\text { total }\end{array}$ & 70 & 2.21 & 2.30 & 0.275 & 1.66 & 2.76 & 0 & 9 \\
\hline
\end{tabular}

Of the 71 patients with hypertension, 30 occurred along the Queensland coast and 41 were stings received offshore. The highest hypertensive recording for the morphine group was 210/135 mmHg (MAP $160 \mathrm{mmHg}$ ) for a male aged 21 years who was stung at Whitehaven Beach in the Whitsundays. On arrival at the receiving medical facility his BP was 155/108 $\mathrm{mmHg}$ (MAP $124 \mathrm{mmHg}$ ). The highest recording for the magnesium group was 205/111 mmHg (MAP $142 \mathrm{mmHg}$ ) for a male aged 46 years who was stung at Yarrabah in Cairns. On arrival at the receiving medical facility his BP was 144/82 $\mathrm{mmHg}$ (MAP $103 \mathrm{mmHg}$ ). No episodes of electrocardiogram abnormalities associated with magnesium administration were documented.

\section{Symptoms}

All patients presented with symptoms suggestive of a catecholamine storm after submersion in a marine environment, with each patient presenting with a minimum of three symptoms. In this instance, the term 'generalised pain' refers to pain/cramping in the extremities (Figure 5).

\section{Travel time}

The mean response time from receiving the call to arriving at the patient for the combined groups was 41 minutes: 28 minutes for the morphine group and 46 minutes for the magnesium group. For all coastal calls, the mean response time was 22 minutes and 51 minutes for offshore responses. The longest duration from call to arriving at the patient was 2 hours and 44 minutes. All incidents occurred during the designated Queensland stinger season (October to May) with the majority (58\%) occurring between 2:30 and 6:30 pm.
Table 5. Mean BP of hypertensive patients in the morphine and magnesium groups, pre- and post-treatment

\begin{tabular}{|c|c|c|c|}
\hline $\begin{array}{c}\text { Pre- } \\
\text { treatment } \\
\text { hypertensive } \\
\text { patients }\end{array}$ & $\begin{array}{l}\text { Systolic BP } \\
\text { mmHg mean }\end{array}$ & $\begin{array}{l}\text { Diastolic BP } \\
\text { mmHg mean }\end{array}$ & $\begin{array}{c}\text { MAP mmHg } \\
\text { mean }\end{array}$ \\
\hline $\begin{array}{l}\text { Morphine } \\
\text { group } \\
95 \% \mathrm{Cl} \text { for } \\
\text { mean }\end{array}$ & $\begin{array}{l}159 \\
\mathrm{Cl} \text { [149-170] }\end{array}$ & $\begin{array}{l}102 \\
\mathrm{Cl}[95-108]\end{array}$ & $\begin{array}{l}121 \\
\mathrm{Cl}[113-129]\end{array}$ \\
\hline $\begin{array}{l}\text { Magnesium } \\
\text { group } \\
95 \% \mathrm{Cl}\end{array}$ & $\begin{array}{l}155 \\
\mathrm{Cl}[151-160]\end{array}$ & $\begin{array}{l}95 \\
\mathrm{Cl} \text { [92-99] }\end{array}$ & $\begin{array}{l}114 \\
\mathrm{Cl}[110-118]\end{array}$ \\
\hline$p$ value & $p=.487$ & $p=.074$ & $p=.076$ \\
\hline \multicolumn{4}{|c|}{ Post-treatment hypertensive patients } \\
\hline $\begin{array}{l}\text { Morphine } \\
\text { group } \\
95 \% \mathrm{Cl} \text { for } \\
\text { mean }\end{array}$ & \begin{tabular}{|l}
146 \\
$\mathrm{Cl}$ [139-155]
\end{tabular} & $\begin{array}{l}93 \\
\mathrm{Cl} \text { [84-102] }\end{array}$ & $\begin{array}{l}111 \\
\mathrm{Cl}[103-119]\end{array}$ \\
\hline $\begin{array}{l}\text { Magnesium } \\
\text { group } \\
95 \% \mathrm{Cl}\end{array}$ & $\begin{array}{l}138 \\
\mathrm{Cl} \text { [132-144] }\end{array}$ & $\begin{array}{l}84 \\
\mathrm{Cl}\left[\begin{array}{ll}80 & 88\end{array}\right]\end{array}$ & \begin{tabular}{|l}
101 \\
$\mathrm{Cl}[96-105]$
\end{tabular} \\
\hline$p$ value & $p=.120$ & $p=.027$ & $p=.028$ \\
\hline
\end{tabular}

\section{Location of sting}

On reviewing the free text for sting locality on the patient, 69 patients $(62 \%)$ were stung in locations that could have been protected by an approved full body stinger suit/wet suit. The remaining 22 patients (20\%) were stung on locations that are 
generally exposed, such as the face, neck, hands and feet. Of the remaining 21 patients, seven (6\%) had multiple sting locations and for 14 patients (12\%) the paramedic was unable to locate the sting location and/or failed to document the locality (Figure 6).

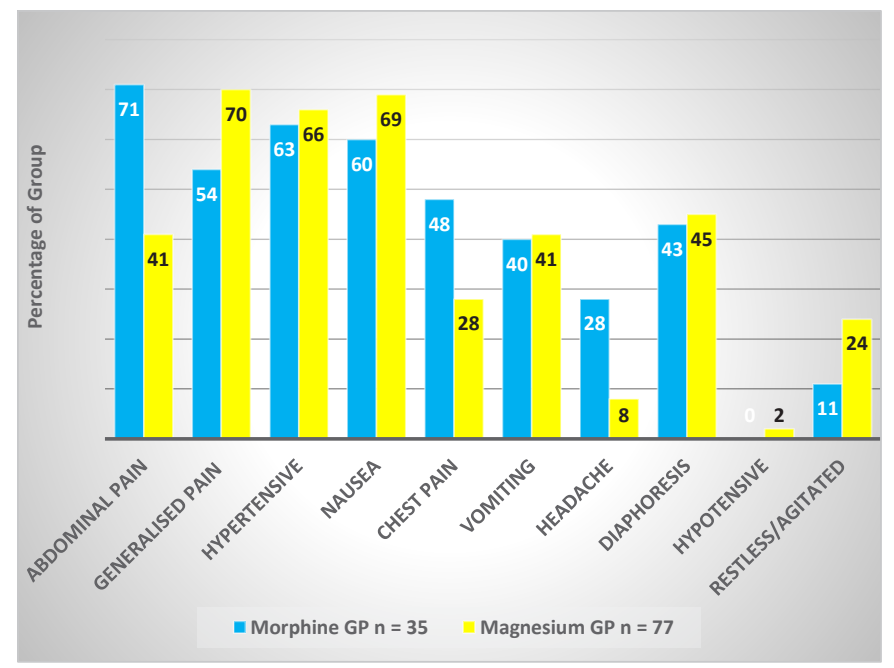

Figure 5. Signs and symptoms

\section{Discussion}

This study suggests that the use of magnesium in conjunction with morphine is more effective at managing pain as well as reducing $\mathrm{BP}$ in those who developed hypertension. The early intervention in the acute pain setting (17) along with the magnesium enhancing the effects of morphine (18) and the magnesium group having double the patient contact time of those just receiving morphine, may explain the desirable outcome in pain management. Current research supports the notion that the symptomology in IS is the result of a catecholamine storm triggered by specific neurotoxins within the venom $(3,5)$. Magnesium not only has a depressant activity on adrenal release of catecholamines but is also known to produce a fall in vascular resistance in hyperadrenergic conditions (7). This pharmacodynamic process explains the reduction in overall hypertension with $59 \%$ of the hypertensive patients in the magnesium group being normotensive post-treatment.

The QAS protocol allows for a higher quantity of magnesium to be administered than other recommendations, such as those made by the Irukandji Taskforce $(0.15 \mathrm{mmol} / \mathrm{kg})(19)$. A double-blinded randomised controlled trial with magnesium was undertaken by the Cairns Hospital from November 2003 to May 2007 (8). The trial had to be stopped before completion with QAS authorising paramedics to administer magnesium in an IS setting. However, the trial determined that there appears to be no difference in pain management in those patients who received magnesium over those who received the placebo after they presented at the emergency department. However, without following strict rules on terminating a trial early, the interpretation of the data may be misleading $(20,21)$. The magnesium dose was based on Corkeron's original paper of 2003 and was less than the dose currently advised by the Irukandji Taskforce $(6,19)$. QAS magnesium loading dose is twice that of the trial and four times greater than the maintenance dose (22).

Over half of these cases could have been prevented through the use of a stinger suit. The efficiency of such clothing was reviewed in 2009 and reported, 'In general, the tighter the fabric weave, the better tentacle exclusion, and the smoother the fabric, the more resistant to adherence. Lycra is vulnerable to crushing of tentacles through the fabric but appears to be the best choice for routine use stinger-protective clothing' (23). As discussed, the causative jellyfish of IS is attributed to stings from jellyfish of the Class Cubozoa; Order Carybdeida $(1,2)$.

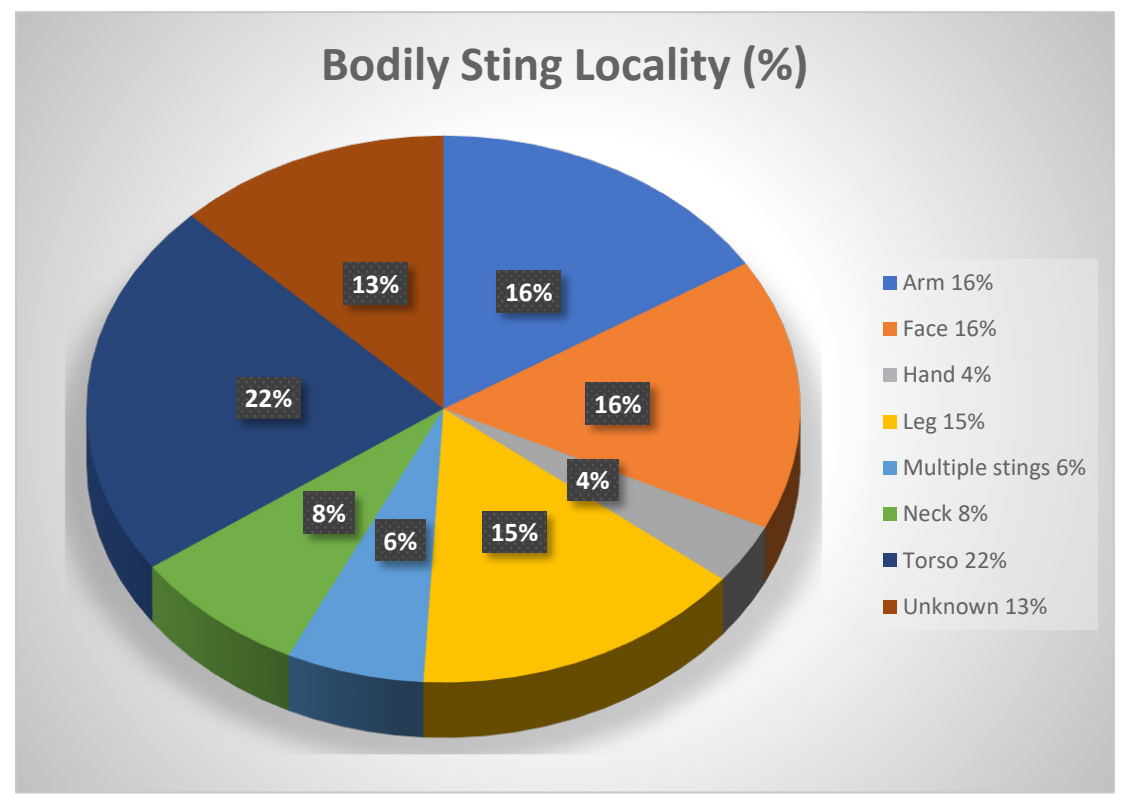

Figure 6. Reported sting locality on patients $(n=98)$ 
Some of these cubed shaped jellyfish can be exceptionally small, with bell size starting from $0.5-10 \mathrm{~mm}$ in diameter, as in Carukia barnesi (1). Some of the jellyfish responsible for causing IS have been identified along the Queensland coastline and from Bundaberg onwards they share the waters with the box jellyfish (Chironex fleckeri). This is a large cuboidal jellyfish with a bell size of up to $30 \mathrm{~cm}$ capable of inflicting extremely painful stings, extensive lesions with severe stings resulting in cardiac arrest within minutes. Due to the potential danger this animal presents to bathers along the coast of tropical regions of Australia, popular bathing regions have specific netted areas that will protect bathers from large specimens and possible fatal stings. Unfortunately, the majority of jellyfish known to cause IS are a result of the smaller Carybdea jellyfish are capable of entering the netted area. Of the recorded cases in this review, $12 \%$ occurred within these netted and patrolled regions.

These netted areas are typically called 'stinger nets' or 'stinger enclosures' and may give the wrong impression to visitors to the region (even locals) that they provide protection against all jellyfish.

\section{Limitations}

While the data was extensively interrogated to identify IS cases it is possible that some cases may have been missed. Although the MPDS is effective at determining the urgency of the response, it has not demonstrated high sensitivity for clinical accuracy (24). There is also the possibility of bias due to magnesium being only available to ICPs at the first part of this study. Some cases could have been missed due to the lack of detailed documentation in the patient report form thus not allowing the diagnosis of IS based on descriptive symptomology. It is further acknowledged that this is a cases series retrospective population study with all the limitations which come with this type of study. However, it does have the benefits of having a clear timeline as to the commencement of magnesium illustrating any change in either groups.

\section{Conclusion}

This study suggests that treating patients with morphine and magnesium is more effective than using morphine alone. QAS's use of a higher dose of magnesium may explain the apparent success that the service is having. Unfortunately, blood serum levels cannot be tested in the pre-hospital setting, so it is impossible to say whether the QAS magnesium dose is reaching the level of magnesium toxicity. With the single trial having to be stopped before completion, the current use of magnesium in practice is based on efficacy reported in a case series. It is felt that a larger trial is required to ascertain the efficacy of magnesium in managing this painfully debilitating syndrome. Until such time, magnesium should be considered in conjunction with morphine, or another opioid in patients who are displaying clinical features of IS.

\section{Acknowledgements}

The authors wish to thank the custodians of the data, Queensland Ambulance Service for their cooperation and assistance with this research project. Also, Mr Sidumo Masango, Statistical Lecturer at the University of eSwatini for proofing the statistical methods used in this research.

\section{Conflict of interest}

The authors of this paper report no competing interests. Each author of this paper has completed the ICMJE conflict of interest statement.

\section{References}

1. Gershwin L, Richardson AJ, Winkel KD, et al. Biology and ecology of Irukandji jellyfish (Cnidaria: Cubozoa). Adv Mar Biol 2013;66:1-85.

2. Gershwin L-A. Two new species of box jellies (Cnidaria: Cubozoa: Carybdeida) from the central coast of Western Australia, both presumed to cause Irukandji syndrome. Records of the Western Australian Museum 2014;29:10-9.

3. Tibballs J, Li R, Tibballs HA, Gershwin LA, Winkel KD. Australian carybdeid jellyfish causing 'Irukandji syndrome'. Toxicon 2012;59:617-25.

4. Gershwin LA, de Nardi M, Winkel KD, Fenner PJ. Marine stingers: review of an under-recognized global coastal management issue. Coastal Management 2010;38:22-41.

5. Tibballs J, Hawdon G, Winkel K. Mechanism of cardiac failure in Irukandji syndrome and first aid treatment for stings. Anaesth Intensive Care 2001;29:552.

6. Corkeron MA. Magnesium infusion to treat Irukandji syndrome. Med J Aust 2003;178:411.

7. Fawcett WJ, Haxby EJ, Male DA. Magnesium: physiology and pharmacology. Br J Anaesth 1999;83:302.

8. McCullagh N, Pereira P, Cullen P, et al. Randomised trial of magnesium in the treatment of Irukandji syndrome. Emerg Med Australas 2012;24:560-5.

9. Rathbone J, Franklin R, Gibbs C, Williams D. Role of magnesium sulphate in the management of Irukandji syndrome: a systematic review. ibid. 2017;29:9-17.

10.Fenner PJ. Dangerous Australian box jellyfish. SPUMS J 2005;35:76-83.

11. Carrette TJ, Underwood AH, Seymour JE. Irukandji syndrome: a widely misunderstood and poorly researched tropical marine envenoming. Diving Hyperb Med 2012;42:214-23.

12. Queensland Ambulance Service. Information Privacy Act 2009 (Qld). 2017. Available at: www.ambulance.qld.gov.au/ privacy.html [Accessed 15 May 2017).

13.Service. QA. Clinical practice manual; drug therapy protocols. Available at: https://ambulanceqldgovau/ clinicalhtml [Accessed 24 November 2016]. 


\section{References (continued)}

14.Parker L. Authorisation for the use of magnesium sulphate in Irukandji syndrome. In: Rathbone J, editor. Dates as to when magnesium was authorised for the use in Irukandji Syndrome. Editor QAS: Executive Manager-Clinical Policy Development; 2017.

15.Clawson JJ, Dernocoeur KB. Principles of emergency medical dispatch: Priority Press; 2003.

16. Fields LE, Burt VL, Cutler JA, et al. The burden of adult hypertension in the United States 1999 to 2000: a rising tide. Hypertension 2004;44:398-404.

17.Carr DB, Goudas LC. Acute pain. Lancet 1999;353:2051-8.

18. Begon S, Pickering G, Eschalier A, Dubray C. Magnesium increases morphine analgesic effect in different experimental models of pain. Anesthesiology 2002;96:62732.

19.Pereira P. Irukandji Taskforce Guidelines for the emergency management of Irukandji syndrome. Available at: http:// archiverubicon-foundationorg/xmlui/handle/123456789/9372 [Accessed 24 November 2016].

20.Pocock SJ. When to stop a clinical trial. BMJ 1992;305:23540.

21.Pocock SJ. When (not) to stop a clinical trial for benefit. JAMA 2005;294:2228-30.

22. Rathbone J, Franklin R, Gibbs C, Williams D. Role of magnesium sulphate in the management of Irukandji syndrome: a systematic review. Emerg Med Australas 2017;29:9-17.

23.Gershwin L-a, Dabinett K. Comparison of eight types of protective clothing against Irukandji jellyfish stings. J Coas Res 2009;117-30.

24. Turner J. Building the evidence base in pre-hospital urgent and emergency care: a review of research evidence and priorities for future research. The University of Sheffield Medical Care Research Unit Sheffield, UK: Department of Health; 2010. 